University of Nebraska - Lincoln

DigitalCommons@University of Nebraska - Lincoln

Faculty Publications, Department of Psychology

Psychology, Department of

7-1-2004

\title{
Gender and Age Differences in Brazilian Children's Friendship Nominations and Peer Sociometric Ratings
}

\author{
Maria Rosario de Guzman \\ University of Nebraska-Lincoln, mguzman2@unl.edu \\ Gustavo Carlo \\ University of Nebraska-Lincoln, carlog@missouri.edu \\ Lenna L. Ontai \\ University of California, Davis \\ Silvia H. Koller \\ Universidade Federal do Rio Grande do Sul, Brazil \\ George P. Knight \\ Arizona State University, george.knight@asu.edu
}

Follow this and additional works at: https://digitalcommons.unl.edu/psychfacpub

Part of the Psychiatry and Psychology Commons

de Guzman, Maria Rosario; Carlo, Gustavo; Ontai, Lenna L.; Koller, Silvia H.; and Knight, George P., "Gender and Age Differences in Brazilian Children's Friendship Nominations and Peer Sociometric Ratings" (2004). Faculty Publications, Department of Psychology. 52.

https://digitalcommons.unl.edu/psychfacpub/52

This Article is brought to you for free and open access by the Psychology, Department of at DigitalCommons@University of Nebraska - Lincoln. It has been accepted for inclusion in Faculty Publications, Department of Psychology by an authorized administrator of DigitalCommons@University of Nebraska - Lincoln. 


\title{
Gender and Age Differences in Brazilian Children's Friendship Nominations and Peer Sociometric Ratings
}

\author{
Maria Rosario T. de Guzman, ${ }^{1}$ Gustavo Carlo, ${ }^{1,5}$ Lenna L. Ontai, ${ }^{1,2}$ \\ Silvia H. Koller, ${ }^{3}$ and George P. Knight ${ }^{4}$
}

\begin{abstract}
The purpose of this study was to examine gender-and age-related patterns of friendship preferences among Brazilian children. In particular, we examined: (a) children's same-sex friendship preference, and its greater intensity among older children; (b) higher exclusivity among girls and higher inclusiveness among boys; and (c) generally higher exclusivity and inclusiveness among older children. Participants were 210 (110 boys, 100 girls) public school students from Brazil who ranged in age from 3.0 to 10.5 years of age. Children were asked to nominate their best friends and to rate how much they liked and disliked each of their other classmates. Children generally nominated more of same-sex peers as best friends and gave more negative ratings to their cross-sex peers. These same-sex preferences were more intense at the older age groups. Girls and older children gave more negative peer ratings and nominated fewer best friends than boys and younger children. However, the oldest age group gave significantly fewer negative peer ratings than did the younger groups - both in their same-sex and overall negative peer ratings. Results are generally consistent with patterns found in prior studies with children from the United States, but unique gender and age-related patterns also emerged.
\end{abstract}

KEY WORDS: friendships; gender; Brazilian children.

Empirical studies on children's peer relationships document a number of gender-and age-related patterns in their friendships. One of the most recorded patterns in peer relationships is the tendency to prefer friends of the same sex (e.g., Belle, 1989; Feiring \& Lewis, 1987; Pitcher \& Schultz, 1983). This phenomenon has been observed in children as young as 33 months (Jacklin \& Maccoby, 1978), and appears to increase in intensity with age until middle childhood (Belle, 1989; Benenson, Apostoleris, \& Parnass, 1998; Maccoby, 1988, 1990). This same-sex friendship preference is a robust phenomenon, observed across

\footnotetext{
${ }^{1}$ University of Nebraska-Lincoln

${ }^{2}$ Present address: University of California, Davis

${ }^{3}$ Universidade Federal do Rio Grande do Sul, Brazil

${ }^{4}$ Arizona State University

${ }^{5}$ Corresponding author: Department of Psychology, University of Nebraska_Lincoln, Lincoln, Nebraska 68588-0308; e-mail:gcarlo1@unl.edu
}

children's interactions (e.g., Boyatzis, Mallis, \& Leon, 1999; La Freniere, Strayer, \& Gauthier, 1984), their nominations of friends (e.g., Graham, Cohen, Zbikowski, \& Secrist, 1998), and their sociometric ratings of peers (Lockheed, 1986).

In addition, early peer friendships have been found to differ considerably between girls and boys and across age groups. For example, girls' friendships and social networks tend to be smaller in size (Belle, 1989; Benenson, 1990, 1993; Berndt \& Hoyle, 1985; Lever, 1976; Waldrop \& Halverson, 1975) but more intimate than boys' friendships and social networks (Belle, 1989; Furman \& Buhrmester, 1985; Lansford \& Parker, 1999; Pitcher \& Schultz, 1983). Boys have been found to prefer to play outdoors, to play longer, to play more competitive games, and to have more age-heterogeneous groups than girls do (Lever, 1976). 
With regard to developmental changes, children's peer relationships have been described as evolving on a variety of levels - from the intrapersonal to the interpersonal, on dyadic and group levels (Rubin, Bukowski, \& Parker, 1998). For example, older children spend more time with peers (Feiring \& Lewis, 1989) and attribute more importance to peer relationships than do younger children (Berndt, 1981; Berndt \& Hoyle, 1985; Buhrmester \& Furman, 1987; Pitcher \& Schultz, 1983). Older children's friendships also tend to be more stable (Berndt, 1981; Berndt \& Hoyle, 1985), and, at least for girls, more intimate (Buhrmester \& Furman, 1987). Lastly, children's conceptions of friendship evolve to focus on more affective, motivational, and prosocial intentions and less on external characteristics (Furman \& Bierman, 1983). Thus, with age, children's friendships become more delineated and stable, and conceptions of friendship become more sophisticated. Children's friendships additionally tend to become more central, more exclusive, and less transient with age.

Although the various gender-and age-related patterns in children's friendships are well represented in the empirical literature, the study of those patterns among children outside the United States has been mostly neglected. There is reason to believe that children's peer relationships might not necessarily be similar across cultures. Ecological theorists argue that children's relationships can differ as a function of the structure and other aspects of the environments in which they are raised (Tietjen, 1989). Different immediate environments offer different opportunities for interactions, and there are studies that suggest that children's behaviors and ways of interacting can vary in ways consistent with contextual factors (e.g., Benenson, Markovits, Roy, \& Denko, 2003; Donohue, Perry, \& Weinstein, 2003).

In addition, societies differ considerably in their belief systems and attitudes toward socializing children that could ultimately be reflected in children's early relationships. For example, it has been suggested that parental values and their views about independence and interdependence, and views regarding the importance of peers and social competence, together influence eventual peer interaction patterns (Schneider, 1993).

Indeed, some aspects of children's friendships have been found to differ around the world, though some of the cross-cultural findings are consistent with patterns found in children's friendships in the United States. After re-analyzing observational data from a wide sampling of cultures around the world, for example, Whiting and Edwards (1988) reported gender-segregating patterns in children's interactions across societies, but found some cross-cultural differences in the relative amounts of time younger and older children spent in same-sex settings. Similarly, Harkness and Super (1985) found same-sex friendship preferences among children in Kenya, but the pattern emerged about 6 years later than it does in the United States. This relatively late emergence of samesex friendship preference coincided with parental and social expectations at that age, such as the allocation of particular tasks to girls and boys and the relative freedom they are given, which result in the permitted choice of companions. Unfortunately, little else is known regarding the extent to which the same patterns can be found among children outside the United States. It appears that although some of the patterns, such as samesex preference, do emerge in children of other societies, their timing and manifestation are sometimes different. Needless to say, there is a need to augment research on children's peer relationships outside the United States in order better to understand the extent to which age-and gender-related patterns are or are not universal.

\section{This Study: Brazilian Children}

This study represents an exploratory examination of the friendships and peer relationships of children in Brazil. The goal was to examine whether some of the robust age-and gender-related differences found in prior empirical literature would be found in Brazilian children. On the basis of the theory and research reported above, the age-and gender-related patterns we examined include (a) children's same-sex friendship preference, and its greater intensity among older children; (b) higher exclusivity among girls and higher inclusiveness among boys; and (c) generally higher exclusivity and inclusiveness among older children. In addition, because some researchers (Sippola, Bukowski, \& Noll, 1997; Smith, Davidson, \& Ball, 2001) have suggested that children's bias toward same-sex friendship and interactions can be a function of distinct dimensions (e.g., liking same-sex peers and disliking cross-sex peers), we examined both best friend nominations and negative peer ratings.

The sample for this study is from the southern-most region of Brazil, which is considered to be the most Westernized and industrialized in the country (Lang, 1988; 
Poppino, 1973). This area of Brazil is relatively highly populated compared to the other regions of the country, and is the center of the country's agriculture, technology, and manufacturing. By many measures, the quality of life in this area is also higher than that of other parts of Brazil with lower infant mortality rates, higher income, and a high rate of education among children. Porto Alegre has 1.2 million inhabitants, and it is the Brazilian state capital with the best quality of life. The population of Porto Alegre is mostly of European descent.

On a macrosocietal level, scholars have suggested that Brazilians tend more toward collectivism rather than individualism (Gouveia, de Albuquerque, Clemente, \& Espinosa, 2002; Gouveia \& Ros, 2000) and that they have a strong familistic orientation (Schurz, 1964; Smith, 1972; Topik, 1991). On a microsocietal level, the classroom context of Brazilian children is somewhat different from what U.S. children experience. For example, Brazilian children from public schools attend classes $4 \mathrm{hr}$ per day, 5 days per week, whereas most children in U.S. public schools attend classes approximately 7$8 \mathrm{hr}$ per day, 5 days per week. Like many U.S. children, Brazilian school children have mixed-sex classrooms, though this sometimes changes with the grade level. Preadolescent Brazilian school children have fewer mixed-sex classrooms than Brazilian elementary schoolaged children. Furthermore, school children from Brazil have both nonstructured and organized activities, and teachers tend to gender mix the groups for the latter. Together, these macro-and microlevel characteristics might exert some influence on the interactions of Brazilian children with their peers, though it is unclear how the patterns might emerge given the lack of studies that directly examine peer friendship preferences in Brazilian school children.

Although the exploratory nature of this study makes it difficult to develop specific hypotheses, some broad patterns can be expected based on the existing literature on peer relationships found in the United States and in other select countries. First, age differences are expected in the friendship preferences of Brazilian children and adolescents. As children enter into adolescence, peer friendships become increasingly important and take a more prominent role in their social networks (Berndt \& Hoyle, 1985). At the same time, increasing cognitive sophistication better allows children to delineate who their friends are and to define friends in terms of less superficial factors. Indeed, children's friend- ships have been found to differ in their nature across age groups (Rubin et al., 1998). As such, older Brazilian children were expected to identify fewer friends than younger children and also to rate a higher number of classmates negatively. Second, because of the robustness of findings of gender segregation among children, and because some studies do indicate that same-sex preferences exist among children outside the United States (e.g., Whiting \& Edwards, 1988), a same-sex preference was also hypothesized among Brazilian children. However, there were no specific expectations regarding whether this preference would increase with age or at what age it emerges. As was the case in the earlier cross-cultural studies of this phenomenon (Harkness \& Super, 1985; Whiting \& Edwards, 1988), it is difficult to predict specific patterns in gender segregation because of various culture-or context-specific factors. Lastly, on the basis of research regarding gender differences in the size of friendship groups, girls were expected to have or name more friends and rate more peers negatively than boys were.

\section{METHOD}

\section{Participants}

Participants were 210 Brazilian students (110 boys, 100 girls) from predominantly White, middle-class public schools in an urban area in southeast Brazil (Porto Alegre, Rio Grande do Sul). Most of these children came from two-parent households with parents who were selfemployed in small businesses and with approximately 11-15 years of education. Children's ages ranged from 3.0 to 10.5 years with a mean of 6.8 years.

Participants were divided into four age groups that result in relatively equal numbers of participants-3260 months (27 boys, 28 girls), 61-84 months (26 boys, 27 girls), 85-108 months (32 boys, 29 girls), and 109131 months ( 25 boys, 15 girls). These age groups also roughly correspond to divisions in the Brazilian school structure, which includes preschool, early elementary, late elementary, and middle school. The numbers of classes surveyed for each age group was 5 in preschool, 7 in early elementary, 4 in late elementary, and 3 in middle school. The mean number of students for each class within each age group was $18.89(\mathrm{SD}=3.83), 12.60$ $(\mathrm{SD}=3.12), 23.57(\mathrm{SD}=3.35)$, and $26.90(\mathrm{SD}=0.63)$, respectively. 
Table I. Overall Best Friend Nominations and Negative Ratings (Means and Standard Deviations)

\begin{tabular}{|c|c|c|c|c|c|}
\hline & Preschool & Early elementary & Late elementary & Middle school & Total \\
\hline \multicolumn{6}{|c|}{ Proportion of classmates nominated as best friends } \\
\hline Boys & $0.18(0.09)$ & $0.15(0.06)$ & $0.13(0.04)$ & $0.11(0.02)$ & $0.14(0.07)$ \\
\hline Girls & $0.16(0.06)$ & $0.15(0.03)$ & $0.13(0.03)$ & $0.08(0.02)$ & $0.13(0.05)$ \\
\hline Total & $0.17(0.08)$ & $0.15(0.05)$ & $0.13(0.04)$ & $0.10(0.02)$ & $0.14(0.06)$ \\
\hline \multicolumn{6}{|c|}{ Proportion of classmates rated 5 ("Don 't like at all") } \\
\hline Boys & $0.20(0.17)$ & $0.16(0.11)$ & $0.21(0.19)$ & $0.09(0.09)$ & $0.17(0.15)$ \\
\hline Girls & $0.12(0.10)$ & $0.28(0.23)$ & $0.33(0.25)$ & $0.17(0.18)$ & $0.23(0.22)$ \\
\hline Total & $0.16(0.14)$ & $0.22(0.19)$ & $0.27(0.23)$ & $0.12(0.14)$ & $0.20(0.19)$ \\
\hline
\end{tabular}

\section{Procedure}

Participants were interviewed individually in a room separate from the classroom. Each interview took 10$15 \mathrm{~min}$ and was conducted in their native Brazilian Portuguese language. The first part of the interview entailed asking the child to name all of his or her "melhores amigos" (best friends). Responses for this question were coded for the total number of children named and total named for each gender. Children were asked to limit their responses to include only children within their class.

On the basis of class rosters, children were also asked to rate how much they liked or disliked each of their classmates. A scale of 1-5 was used where $1=$ "gosto como melhor amigo" (like as a best friend); 2 = "gosto muito" (like a lot); 3 = "gosto" (like); 4 = "gosto um pouco" (like a little); and 5 = "não gosto" (do not like). Like the best friend nominations, these scores were coded separately for the number of same-and cross-sex classmates rated.

\section{RESULTS}

To adjust for the size and gender composition of the children's reference groups (i.e., class size and the number of boys and girls in the class), proportion scores were computed for each dependent variable. This was partially based on suggestions by La Freniere et al. (1984) that preference scores should take into account actual reference group composition that might influence scores, or in this case, nominations and ratings. The computation of these scores is described in each section. A series of age $(4$ levels $) \times$ sex $(2$ levels $)$ ANOVA were computed for the overall best friend nominations and the negative peer ratings, and a series of age $(4$ levels $) \times \operatorname{sex}(2$ levels $) \times$ gender of friend $(2$ within- group levels: same-and cross-sex) mixed-group ANOVAs was computed for the gender-specific nominations and ratings. 6

\section{Tests for Inclusiveness: Best Friend Nominations}

For best friend nominations, proportion scores were computed to account for class size. Proportion scores reflect the percentage of classmates nominated as best friends. Descriptive statistics are summarized in Table I. The ANOVA revealed a significant age group difference, $F(3,201)=16.30, M S E=0.01, p<.001$. Results of LSD pairwise comparisons $(p<.05)$ show that the preschool children nominated a significantly higher percentage of best friends than did the other age groups; the middle school children nominated the smallest percentage of best friends.

\section{Tests for Exclusiveness: Classmates Rated as "Don't Like at All"}

For classmates rated as "don't like at all," a proportion score was computed by dividing the total number of 5 ratings ("Don't like at all") by the total number of children rated. Thus, each score reflects the percentage of children in a class rated as "don't like at all." Descriptive statistics are summarized in Table I. The ANOVA revealed a main effect for sex, $F(1,202)=5.86, M S E$ $=0.03, p<.02$; girls rated a higher proportion of classmates negatively, and there was also a main effect for age, $F(3,202)=6.44, p<.001$. LSD pairwise comparisons $(p<.05)$ show that early and late elementary school age children negatively rated more classmates than did preschool and middle school age children. These main effects were subsumed by an age group $\times$ sex interaction, $F(3,202)=3.81, p<.01$.

\footnotetext{
${ }^{6}$ Additional analyses were also conducted using raw scores, which yielded similar but slightly weaker findings.
} 
Simple effects test of the age group $\times$ sex interaction, conducted separately by age group, indicate significant effects of sex for preschool, $F(1,53)=4.06, M S E=$ $0.02, p<.05$, early elementary, $F(1,51)=5.39, M S E=$ $0.03, p<.02$, and late elementary, $F(1,59)=4.64, M S E$ $=0.05, p=.04$ ), but not for the middle school children. Among preschoolers, boys rated a higher proportion of their classmates negatively than did girls; and among early and late elementary children, girls rated a higher proportion of their classmates negatively than did boys.

\section{Same-Sex Preferences: Same-Versus Cross-Sex Best Friend Nominations}

To account for the number of peers nominated and the actual class composition, a relative proportion score was computed for the number of same-and cross-sex peers nominated as best friends. The relative proportion score of same-sex peers nominated $=($ No. of samesex best friends nominated/total number of best friends nominated)/(No. of same-sex classmates/total number of classmates). For example, if a child has 12 same-sex, and 10 cross-sex classmates, and nominates 4 samesex and 2 cross-sex classmates, the corresponding relative proportion score would be (4 same-sex nominations $/ 6$ total nominations $) /(12$ same-sex classmates/22 total classmates $)=1.22$. Thus, the same-sex nomination relative proportion scores reflect the degree of deviation between the ratio of same-to cross-sex classmates nominated, and the actual gender composition of the class. Similar scores were computed for cross-sex nominations. Descriptive statistics are summarized in Table II.

A mixed-groups ANOVA was conducted to test for age $(4$ levels $) \times$ sex $(2$ levels $) \times$ gender of best friend ( 2 within-group levels: same-and cross-sex) differences in the relative proportion of same-and cross-sex nomi- nations. Results revealed significant effects of gender of best friends, $F(1,200)=578.37, M S E=0.98, p<.001$, sex, $F(1,200)=31.36, p<.001$, and age, $F(3,200)=$ $3.41, p<.02$. These were subsumed by gender of best friends $\times$ age, $F(3,200)=13.04, M S E=0.98, p<.001$, and age $\times$ sex, $F(3,200)=5.34, M S E=0.06, p<.001$, interactions.

Simple effects test of the gender of best friends $x$ age interaction, conducted separately by age showed significant effects of gender of friend for all age groups-preschool, $F(1,54)=45.25, M S E=0.54, p$ $<.001$, early elementary, $F(1,50)=105.57, M S E=0.52$, $p<.001$, late elementary, $F(1,60)=293.59, M S E=0.38$, $p<.001$, and middle school, $F(1,40)=406.63, M S E=$ $0.16, p<.001$. In each of these age groups, more samesex compared to cross-sex best friends were nominated. Simple effects test of the sex $\times$ age interaction, conducted separately by sex, revealed no simple effects for boys, and an effect of age for girls, $F(3,95)=0.93, M S E$ $=0.16, p<.001$. LSD pairwise comparisons $(p<.05)$ revealed that the late elementary school girls nominated a higher proportion of same-sex in contrast to cross-sex best friends, compared to all other girls.

\section{Same-Sex Friendship Preferences: Same-and Cross- Sex Classmates Rated as "Don't Like at All"}

Relative proportion scores were computed for negative peer ratings in a manner similar to those computed for same-and cross-sex best friend nominations. To examine the number of same-sex in relation to cross-sex classmates rated as "don't like at all," a mixed groups ANOVA was conducted to test age $(4$ levels $) \times \operatorname{sex}(2$ levels) $\times$ gender of best friend ( 2 within-group levels: same-and cross-sex) differences in the relative proportion same-to cross-sex ratings. Descriptive statistics are summarized in Table III.

Table II. Same- and Cross-Sex Nominations Relative Proportion Scores (Means and Standard Deviations)

\begin{tabular}{|c|c|c|c|c|c|}
\hline & Preschool & Early elementary & Late elementary & Middle school & Total \\
\hline \multicolumn{6}{|c|}{ Proportion of same-sex best triend nominations } \\
\hline Boys & $2.30(1.23)$ & $2.31(1.35)$ & $2.63(0.75)$ & $2.64(0.49)$ & $2.47(1.01)$ \\
\hline Girls & $1.75(0.97)$ & $2.54(0.76)$ & $2.72(0.80)$ & $1.94(0.68)$ & $2.27(0.91)$ \\
\hline Total & $2.02(1.13)$ & $2.42(1.09)$ & $2.67(0.77)$ & $2.37(0.66)$ & $2.38(0.97)$ \\
\hline \multicolumn{6}{|c|}{ Proportion of cross-sex best friend ncminations } \\
\hline Boys & $0.70(0.87)$ & $0.46(0.81)$ & $0.13(0.49)$ & $0.00(0.00)$ & $0.32(0.69)$ \\
\hline Girls & $0.71(0.71)$ & $0.31(0.68)$ & $0.14(0.44)$ & $0.13(0.34)$ & $0.34(0.63)$ \\
\hline Total & $0.71(0.79)$ & $0.38(0.75)$ & $0.13(0.46)$ & $0.05(0.22)$ & $0.33(0.66)$ \\
\hline
\end{tabular}


Table III. Same- and Cross-Ser Negative Ratings Relative Proportion Soores (Means and Standard Deviaticns)

\begin{tabular}{|c|c|c|c|c|c|}
\hline & Preschool & Early elementary & Late elementary & Middle school & Total \\
\hline \multicolumn{6}{|c|}{ Proportion of same-sex negative ratings } \\
\hline Boys & $0.80(0.62)$ & $0.67(0.58)$ & $0.51(0.55)$ & $1.20(0.60)$ & $0.77(0.63)$ \\
\hline Girls & $1.11(0.78)$ & $0.90(0.79)$ & $0.32(0.45)$ & $0.89(0.69)$ & $0.78(0.74)$ \\
\hline Total & $0.94(0.70)$ & $0.79(0.70)$ & $0.42(0.51)$ & $1.07(0.65)$ & $0.78(0.68)$ \\
\hline \multicolumn{6}{|c|}{ Proportion of cross-sex negative ratings } \\
\hline Boys & $1.08(0.70)$ & $1.33(0.64)$ & $1.59(0.60)$ & $0.81(0.92)$ & $1.22(0.75)$ \\
\hline Girls & $0.91(0.80)$ & $1.14(0.67)$ & $1.42(0.36)$ & $1.07(0.63)$ & $1.15(0.64)$ \\
\hline Total & $1.00(0.74)$ & $1.23(0.65)$ & $1.50(0.50)$ & $0.92(0.81)$ & $1.19(0.70)$ \\
\hline
\end{tabular}

Results revealed significant effects for gender of friend, $F(1,171)=13.91, M S E=0.82, p<.001$, subsumed by a gender of friend $\times$ age interaction, $F(3,171)$ $=7.62, M S E=7.62, p<.001$. In addition, there was an age $\times$ sex interaction, $F(3,171)=9.03, M S E=0.03, p$ $<.001$. Follow-up of the gender of friend $\times$ age interaction revealed effects of gender of friend for the early, $F(1,49)=5.41, M S E=0.89, p<.02$, and late elementary children, $F(1,49)=62.01, M S E=0.47, p<.001$. In both age groups, more cross-than same-sex peers were rated negatively. Follow-up of the age $\times$ sex interaction revealed an age effect for boys, $F(3,91)=2.87, M S E=$ $0.07, p<.04$, and girls, $F(3,80)=8.61, M S E=0.05, p$ $<.001$. Follow-up analyses using LSD $(p<.05)$ pairwise analyses indicate that late elementary boys negatively rated more cross-sex classmates than did all other boys. Late elementary girls negatively rated fewer same-sex classmates than all other girls.

\section{DISCUSSION}

This study was an exploratory examination of patterns in the peer and friendship preferences of children in Brazil. The aim was to examine whether gender-and age-related patterns that are well documented among U.S. children are also evident in Brazilian children. A number of interesting results emerged from the analyses.

First, consistent with the hypotheses, older children nominated fewer best friends, and early and late elementary school children rated more classmates negatively than did preschoolers. Past research suggests that older children have more sophisticated views of friendships (Rubin et al., 1998) and draw clearer lines between friends and nonfriends. Thus, although children value friendships more with age, and peer relation- ships become more central as they enter adolescence (Buhrmester \& Furman, 1987), it is possible that their groups of friends also become more differentiated.

However, somewhat unexpectedly, the middle school Brazilian children negatively rated a significantly lower number of children than did both the early and late elementary school children. Two non-mutually exclusive processes might explain this pattern. Perhaps peers become increasingly important as children enter adolescence, and the drop might reflect an unwillingness of older children to rate their peers negatively. Alternatively, children at this age might be more aware of norms, and might therefore show an increased desire to "fit in" the peer group, and thus there is a decline in willingness to rate others negatively. Consistent with this latter possibility, middle school Brazilian children have been reported to show more self-presentational concerns than North American children, and are more aware of norms than are preschoolers (Biaggio, 1976, 1984, 1988). The age-related pattern of differences with older children disliking more peers than younger children merits further investigation.

Second, our results partially support the hypothesized gender differences in the number of friendship nominations and negative ratings. Girls rated more classmates negatively than boys, which suggests a higher degree of exclusivity among girls. No gender difference, however, was found for best friend nominations. Thus, it appears that girls disliked more peers in this sample, but boys did not show a liking for more peers. Research suggests that girls' groups tend to be smaller. Boys have more friends and wider social networks than girls, and girls have fewer friends but more intimate friendships (Belle, 1989; Benenson, 1990, 1993; Berndt \& Hoyle, 1985; Furman \& Buhrmester, 1985; Lansford \& Parker, 1999). However, whether it is because girls dislike more peers or that boys have more friends that underlies this gender difference has not been ful- 
ly examined. In the present sample, it appears that the gender difference in peer preferences is more a function of girls being more exclusive rather than boys being more inclusive. It is interesting that a similar gender difference in negative ratings was not evident in the oldest age group. It is possible that middle school girls and boys both are also concerned with self-presentation and with peer acceptance.

Third, generally consistent with literature on children's same-sex preference, results of both the best friend nominations and the negative peer ratings indicated a clear preference for peers of the same sex. Across the age groups, children nominated more same-sex best friends, and early and late elementary children rated more cross-sex classmates negatively. This finding is compatible with the suggestion that same-sex preference and segregation tendencies are also present among children outside of the United States (Maccoby, 1998).

However, the data deviated somewhat from the patterns documented in the literature with regard to the age differences in negative ratings of cross-and samesex peers. When both girls and boys in the current sample were asked how much they liked or disliked their classmates, the children did not start to show a disproportionately higher dislike for cross-sex peers until the early elementary school age. More-over, this higher proportion of dislike for cross-sex in contrast to same-sex peers was evident in early and late elementary school children, but was not apparent in preschool or in middle school children. That is, among the youngest and oldest age group, Brazilian children here rated just about as many same-and cross-sex peers negatively. In contrast, studies among U.S. children generally indicate a same-sex bias that begins in preschool and continues to increase through middle childhood (e.g., La Freniere et al., 1984). Perhaps these culture-specific patterns of same-sex exclusivity are due to differences in the frequency of mixed-sex activities and the different number of hours that children in Brazil and in the United States spend in school. Clearly, cross-cultural studies are needed to examine and confirm these findings.

Fourth, consistent with prior researchers' assertions (Sippola et al., 1997; Smith et al., 2001), children's peer preferences were variably a function of two distinct processes, namely their liking of particular peers and disliking of others. And although these two factors sometimes were consistent with each other, this was not always the case, that is, the patterns of age differ- ences in negative ratings and best friend nominations did not completely coincide.

Across the four age groups, children consistently nominated more same-sex classmates as best friends. In contrast, early and late elementary school children rated more cross-sex classmates negatively, but the preschool or middle school children did not. More-over, Brazilian girls rated more classmates negatively than did Brazilian boys, but girls did not nominate more best friends than boys did. In addition, same-sex preferences in best friend nominations emerged even among preschoolers, but higher negative ratings of cross-sex peers only emerged among early and late elementary children.

As has been suggested by other researchers (Sippola et al., 1997; Smith et al., 2001), therefore, examinations of children's same-sex friendship preferences should take into account potentially distinct underlying processes, particularly the exclusion or dislike of some peers, and the inclusion or liking of others. Similarly, the nomination of best friends might not necessarily involve the same processes that go into disliking others. For example, best friends might be limited to few people, while disliking can be felt toward many. Moreover, one might dislike others for a host of reasons while calling someone a best friend seems to connote more specific and more exclusive choices. Thus, future studies that examine children's friendships and same-sex friendship preferences, in particular, should take these distinct variables into account.

In summary, interesting patterns emerged in the data to indicate gender and age differences in friendship preferences and negative peer ratings, as well as in the same-sex preferences, of Brazilian children. First, there were gender differences in exclusivity, or dislike of peers starting at the early elementary age. Particularly, girls rated more classmates negatively than did boys. Second, older Brazilian children were simultaneously disliked more peers and nominated more friends than younger children, with the exception that the middle school children gave fewer negative ratings than preschool and elementary school children. And third, there was a clear same-sex bias both in the best friend nominations and negative ratings of peers, though the latter emerged only among early and late elementary school children. These gender-and age-related differences suggest that distinct processes might indeed underlie peer preferences among Brazilian children, that is, that both liking and disliking peers together bring about peer pref- 
erences and that those two variables represent distinct processes. Overall, the findings reiterate the importance of investigating gender and age-related peer preferences in peer relationships and friendships in children from different societies.

\section{ACKNOWLEDGMENTS}

The authors thank the students and staff of the participating schools and Richard Fabes and Stephanie Shepard for their assistance. Funding for this project was provided by a grant from the Office of the Research Council, the American Psychological Association, and the John Templeton Foundation to Gustavo Carlo; grants from the Institute of Ethnic Studies and the Family Research Policy Initiative to Maria de Guzman; a minority fellowship grant from the National Science Foundation to Lenna Ontai, and a Conselho Nacional de Desenvolvimento Cientifico e Tecnologico grant (350383/952) to Silvia H. Koller.

\section{REFERENCES}

Belle, D. (1989). Gender differences in children's social networks and supports. In D. Belle (Ed.), Children's social networks and social supports (pp. 173-188). New York: Wiley.

Benenson, J. (1990). Gender differences in social networks. Journal of Early Adolescence, 10, 472-495.

Benenson, J. (1993). Greater preferences among females than males for dyadic interactions in early childhood. Child Development, 64, 544-555.

Benenson, J., Apostoleris, N., \& Parnass, J. (1998). The organization of children's same-sex peer relationships. In W. M. Bukowski \& A. H. Cillessen (Eds.), Sociometry then and now: Building on six decades of measuring children's experience with the peer group (pp. 5-23). San Francisco: Jossey-Bass.

Benenson, J. F., Markovits, H., Roy, R., \& Denko, P. (2003). Behavioural rules underlying learning to share: Effects of development and context. International Journal of Behavioral Development, 27, 116-121.

Berndt, T. J. (1981). Age changes and changes over time in prosocial intentions and behavior between friends. Developmental Psychology, 17, 408-416.

Berndt, T. J., \& Hoyle, S. G. (1985). Stability and change in childhood and adolescent friendships. Developmental Psychology, 21, 1007-1015.

Biaggio, A. M. B. (1976). A developmental study of moral judgment of Brazilian children and adolescents. Interamerican Journal of Psychology, 10, 71-78.

Biaggio, A. M. B. (1984). Pesquisas em psicologia do desenvolvi- mento e da personalidade [Research in developmental and personality psychology]. Porto Alegre, Brazil: Eduni-Sul.

Biaggio, A. M. B. (1988). Psicologia do desenvolvimento [Developmental psychology]. Petropolis, Brazil: Vozes.

Boyatzis, C. J., Mallis, M., \& Leon, I. (1999). Effects of game type on children's gender-based peer preferences: A naturalistic observational study. Sex Roles, 40, 93-105.

Buhrmester, D., \& Furman, W. (1987). The development of companionship and intimacy. Child Development, 58, 11011113.

Donohue, K., Perry, K. E., \& Weinstein, R. S. (2003). Teachers' classroom practices and children's rejection by their peers. Journal of Applied Developmental Psychology, 24, 91-118.

Feiring, C., \& Lewis, M. (1987). The child's social network: Sex differences from three to six years. Sex Roles, 17, 621-636.

Feiring, C., \& Lewis, M. (1989). The social networks of girls and boys from early through middle childhood. In D. Belle (Ed.), Children's social networks and social supports (pp. 119172). New York: Wiley.

Furman, W., \& Bierman, K. L. (1983). Developmental changes in young children's conceptions of friendship. Child Development, 54, 549-556.

Furman, W., \& Buhrmester, D. (1985). Children's perceptions of the personal relationships in their social networks. Developmental Psychology, 21, 1016-1024.

Gouveia, V. V., de Albuquerque, J. B., Clemente, M., \& Espinosa, P. (2002). Human values and social identities: A study in two collectivist cultures. International Journal of Psychology, 37, 333-342.

Gouveia, V. V., \& Ros, M. (2000). Hofstede and Schwartz's models for classifying individualism at the cultural level: Their relation to macro-social and macro-economic variables. Psicothema, 12(Suppl.), 25-33.

Graham, J. A., Cohen, R., Zbikowski, S. M., \& Secrist, M. E. (1998). A longitudinal investigation of race and sex as factors in children's classroom friendship choices. Child Study Journal, 28, 245-227.

Harkness, S., \& Super, C. M. (1985). The cultural context of gender segregation in children's peer groups. Child Development, 56, 219-224.

Jacklin, C. N., \& Maccoby, E. E. (1978). Social behavior at thirty-three months in same-sex and mixed-sex dyads. Child Development, 49, 557-569.

La Freniere, P., Strayer, F. F., \& Gauthier, R. (1984). The emergence of same-sex affiliative preferences among preschool peers: A developmental/ethological perspective. Child Development, 55, 1958-1965.

Lang, J. (1988). Inside development in Latin America: A report from the Dominican Republic, Columbia, and Brazil. Chapel Hill, NC: University of North Carolina Press.

Lansford, J. E., \& Parker, J. G. (1999). Children's interactions in triads: Behavioral profiles and effects of gender and patterns of friendships among members. Developmental Psychology, $35,80-93$.

Lever, J. (1976). Sex differences in the games children play. Social Problems, 23, 478-487. 
Lockheed, M. E. (1986). Reshaping the social order: The case of gender segregation. Sex Roles, 14, 617-628.

Maccoby, E. E. (1988). Gender as a social category. Developmental Psychology, 24, 755-765.

Maccoby, E. E. (1990). Gender and relationships. American Psychologist, 45, 513-520.

Maccoby, E. E. (1998). The two sexes: Growing up apart, coming together. Cambridge, MA: Bellknap Press.

Pitcher, E. G., \& Schultz, L. H. (1983). Boys and girls at play: The development of sex roles. New York: Bergin \& Garvey.

Poppino, R. E. (1973). Brazil: The land and people (2nd ed.). New York: Oxford University Press.

Rubin, K. H., Bukowski, W., \& Parker, J. G. (1998). Peer interactions, relationships, and groups. In N. Eisenberg (Ed.), Handbook of child psychology: Social and personality development (Vol. 3, pp. 619-700). New York: Wiley.

Schneider, B. H. (1993). Children's social competence in context. Oxford: Pergamon Press.

Schurz, W. L. (1964). Latin America: A descriptive survey. New York: Dutton.

Sippola, L. K., Bukowski, W. M., \& Noll, R. B. (1997). Dimen- sions of liking and disliking underlying the same-sex preference in childhood and early adolescence. Merrill-Palmer Quarterly, 43, 591-609.

Smith, L. T. (1972). Brazil: People and institutions (4th ed.). Baton Rouge: Louisiana State University Press.

Smith, R. B., Davidson, J., \& Ball, P. (2001). Age-related variations and sex differences in gender cleavage during middle childhood. Personal Relationships, 8, 153-165.

Tietjen, A. M. (1989). The ecology of children's social support networks. In D. Belle (Ed.), Children's social networks and social supports (pp. 37-69). New York: Wiley.

Topik, S. (1991). The old republic. In M. L. Conniff \& F. D. McCann (Eds.), Modern Brazil: Elites and masses in historical perspective (pp. 83-102). Lincoln: University of Nebraska Press.

Waldrop, M., \& Halverson, C. (1975). Intensive and extensive peer behavior: Longitudinal and cross-sectional analysis. Child Development, 46, 19-26.

Whiting, B. B., \& Edwards, C. P. (1988). Children of different worlds: The formation of social behavior. Cambridge, MA: Harvard University Press. 